\title{
Effects of respiratory reeducation exercise using a pressure biofeedback unit on the quality of life of persons with stroke
}

\author{
Hyun Seung Kim ${ }^{(1)}$ \\ Department of Medical Sciences, Graduate School of Nambu University, Gwangju, Republic of Korea
}

Objective: The purpose of this study was to confirm the validity of a respiratory retraining exercise using pressure biofeedback units among individuals with stroke as an effective intervention for improving quality of life.

Design: Randomized controlled trial.

Methods: Thirty patients with stroke were recruited as subjects. Among them, 15 patients were randomly assigned to an experimental group performing lumbar stabilization exercise and respiratory retraining exercise, and the other 15 patients were randomly assigned to a control group conducting only lumbar stabilization exercises. Exercises were conducted 3 times a week for 6 weeks, and quality of life was evaluated in the pre-test, 3 weeks and 6 weeks periods. The respiratory retraining exercises were performed using a pressure biofeedback unit and the degree of the quality of life was measured using the Stroke- Specific Quality of Life. For data analysis on the study results, a two-way repeated ANOVA was used in order to observe for changes in the measured variables according to time for both groups. If there was a reciprocal action between the groups and the time in the effect test within the entities, a one-way repeated ANOVA was implemented and was statistically processed.

Results: There was a significant difference in the main effect test between the 2 populations depending on the duration of the experiment (6 weeks) $(p<0.05)$.

Conclusions: The above results showed that respiratory retraining exercises may provide positive effects in the treatment of stroke as the quality of life showed significant differences according to the duration of treatment.

Key Words: Biofeedback, Quality of life, Respiratory, Stroke

\section{Introduction}

Stroke is a disease that damages the brain due to obstruction or rupture of the blood vessels around the brain tissue [1]. Disability recovery after stroke is generally incomplete, and approximately $50 \%$ of patients have persistent neurological damage [2], accompanied by various complications including symptoms such as movement disorders, perception and cognitive disorders, speech disorders, and visual disorders [3]. This is one of the factors that limit daily activities and hinder social participation [4-6]. Lumbar stabilization exercise is an exercise that restores the ability to control muscles and movement, and refers to maintaining proper contraction of the abdominal muscles and controlling and adjusting the neuromuscular system [7]. It is also effective in improving the function and pain of patients with back pain through the activation of the central muscles [8] by strengthening active lumbar-related tissues [9]. Therefore, it is widely used to improve trunk and heart muscle strength [10]. However, incorrect use of various exercise methods performed on patients with low back pain can lead to muscle damage and it is not effective in improving muscle strength. Therefore, in order to compensate for this point, this study used a pressure biofeedback device [11]. The pressure bio-

Received: 3 December, 2020 Revised: 28 December, 2020 Accepted: 28 December, 2020

Corresponding author: Hyun Seung Kim (ORCID https://orcid.org/0000-0002-8052-452X)

Department of Medical Sciences, Graduate School of Nambu University, 1 Nambudae-gil, Gwangsan-gu, Gwangju 62271, Republic of Korea Tel: 82-62-513-4584 Fax: 82-62-970-0492 E-mail: sang6464@hanmail.net

(a) This is an Open-Access article distributed under the terms of the Creative Commons Attribution Non-Commercial License (http://creativecommons.org/licenses/ by-nc/4.0) which permits unrestricted non-commercial use, distribution, and reproduction in any medium, provided the original work is properly cited.

Copyright $@ 2020$ Korean Academy of Physical Therapy Rehabilitation Science 
feedback device is an inelastic device that is connected to a pressure gauge and expands when the internal pressure increases. It was originally developed to evaluate the ability of the abdominal muscles to actively stabilize the lower back [12]. It is used in various studies to test the stability of the lumbar spine [13]. In addition, it is reported that muscle contraction and strength can be visually confirmed, and exercise effects are enhanced by accurately contracting the small muscles in the lumbar spine [14]. The quality of life is also an important factor in the rehabilitation of stroke survivors [15]. Quality of life is an important part of a healthy life as the ultimate goal of any health intervention. However, there are insufficient papers related to the quality of life of individuals with stroke. Quality of life can appear as a complex result of several factors, so analysis and intervention should be conducted. Therefore, in this study, the purpose of this study was to investigate how breathing retraining exercise using a pressure biofeedback device can affect the quality of life of persons with stroke.

\section{Methods}

\section{Participants and procedures}

This study was conducted on 30 individuals with stroke admitted to the Sunhan Nursing Hospital. This study was randomly assigned consisting of 15 subjects in the experimental group who underwent respiration retraining exercise using the lumbar stabilization exercise and the pressure biofeed- back device, and 15 subjects in the control group who performed only the lumbar stabilization exercise. We also recruited those who understood and wished to participate in this study. Consent was obtained after explaining the procedure and purpose of the study to all subjects.

The selection criteria for this study were as follows: those who had an initial stroke event 6 months ago or more, those who had no respiratory problems, those who had no problems with communication, those who did not undergo kidney dialysis, those who could respond to the evaluation form.

The exclusion criteria were those diagnosed with dementia, those who wore pacemakers, those with developmental disabilities, those with complications, and those who had a stroke relapse.

This study was approved by the Institutional Review Board (IRB) of the Nambu University (NBU-IRB-10414782017-HR-017) and was conducted in accordance with the ethical standards of the Helsinki Declaration. On the other hand, if the participant wanted to discontinue while the study was in progress, he or she was excluded from the study. The design of this study was as follows (Figure 1).

\section{Experimental method}

The exercise method of the experimental group was lumbar stabilization exercises for 30 minutes and breathing retraining exercises for 20 minutes, and the control group performed lumbar stabilization exercises. The lumbar stabiliza-

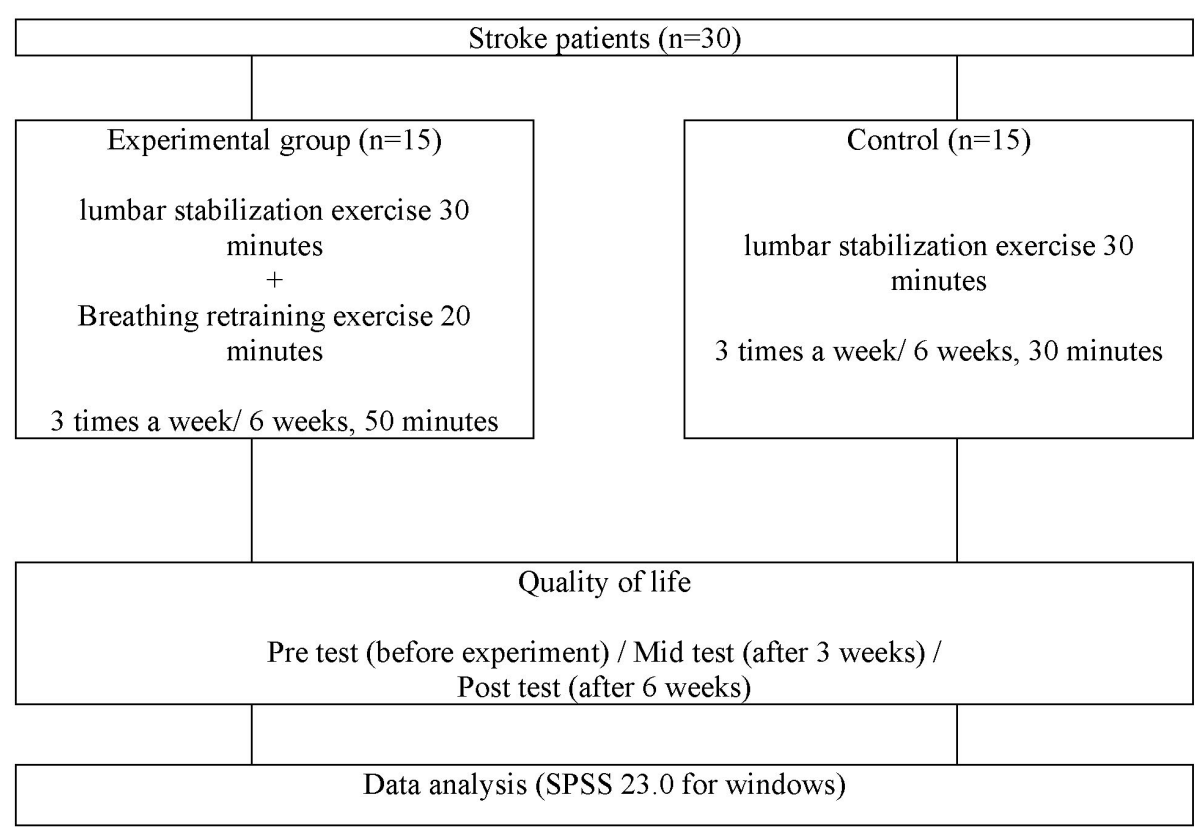

Figure 1. Research design of this study. 
tion exercise method was 10 repetitions for 1 set for a total of 3 sets, and after 1 set a 2 -minute rest period was provided before the next set was performed. The bridge exercise was reconstructed as a lumbar stabilization exercise where the subject lied down on a stable support surface with $45^{\circ}$ of hip flexion and $90^{\circ}$ of knee flexion, the arms were spread out approximately $30^{\circ}$ with the palms facing the ground, and the neck was kept in straight position. At this point, the motion of lifting the trunk from the floor was maintained while maintaining the contraction of the vertebral and abdominal muscles.

The breathing retraining exercise was performed to improve the stability of the sacrum by lower extremity flexion and extension while maintaining a state with no lumbar flexion or rotation through proper contraction of the abdominal muscles. At this time the pressure was dropped to $60 \mathrm{mmHg}$ in the state of increasing the $70 \mathrm{mmHg}$ pressure, which was maintained for 10 seconds and a rest period of 2 minutes was applied before the next set, and a total of 5 sets were applied (Table 1).

\section{Measurement Tools}

\section{Stabilizer pressure bio-feedback}

A pressure biofeedback device was used to measure the constant contractile force of the deep muscles of the lower back. The pressure biofeedback device consists of a meter and a flat pocket pneumatic pump, where the force generated by the contraction of the deep muscles is transferred to the pressure biofeedback device to measure the pressure. The unit is $\mathrm{mmHg}$ [16] (Figure 2).

\section{Stroke-specific quality of life measure (SS-QOL)}

This is an outcome measure developed for stroke survivors, which also includes overlooked areas as a general quality of life assessment. It is also composed of 12 sub-items by Williams et al. [17] and the composition is energy, family role, language use, movement, mood, personal personality, self-help activities, social role, and thinking ability. It consists of upper limb function, visual acuity, and occupation-production activities, and the total score is 49 points minimum and 245 points maximum as measured on a 5-point scale. Reliability of each item is above 0.73 [17].

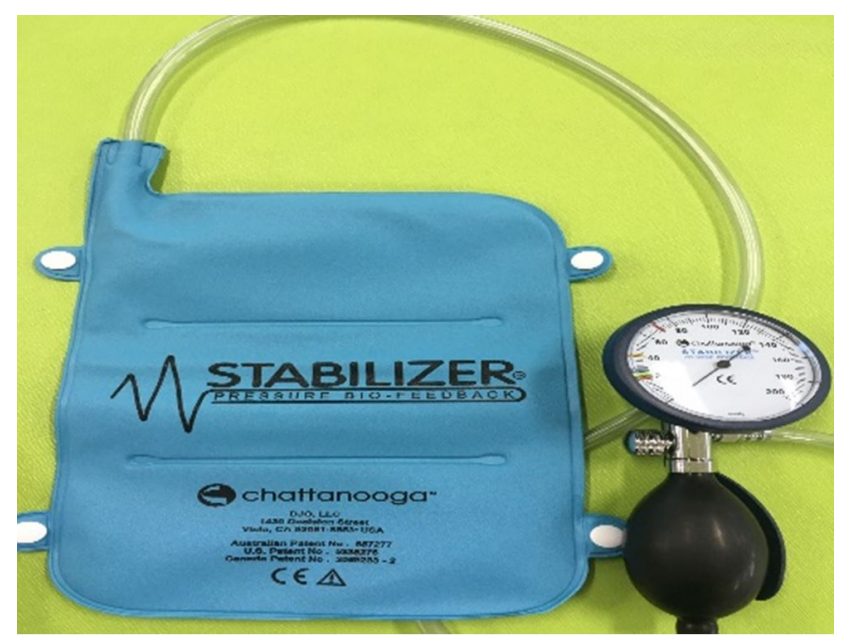

Figure 2. Stabilizer Pressure Bio-Feedback (Chattanooga, chattanooga, TN, USA).

Table 1. Experimental method

\begin{tabular}{|c|c|}
\hline \multicolumn{2}{|l|}{ Exercise method } \\
\hline Lumbar stabilization exercise CG (30 minutes) & 1. Bridge motion on a stable support surface \\
\hline & 2. Lifting your feet on a stable support surface \\
\hline & $\begin{array}{l}\text { 3. Upper body lifting exercise on a stable support } \\
\text { surface }\end{array}$ \\
\hline & 1 Set 10 times \\
\hline & Apply a total of 3 sets \\
\hline & 2 Minutes each break after 1 set \\
\hline \multirow[t]{4}{*}{ Breathing retraining exercise using pressure biofeedback device EG (20 minutes) } & 1. Raising the pressure to $70 \mathrm{mmHg}$ \\
\hline & 2. Maintain pressure at $60 \mathrm{mmHg}$ for 10 seconds \\
\hline & Apply a total of 5 sets \\
\hline & 2 Minutes each break after 1 set \\
\hline
\end{tabular}

EG: experimental group, CG: control group. 


\section{Statistical analysis}

For the analysis and statistical processing of data in this study, the mean and standard deviation values were calculated using the IBM SPSS for Windows, Version 23.0 (IBM Co., Armonk, NY, USA). General characteristics were evaluated using descriptive statistics. In addition, the t-test was performed to test the difference between the groups who performed the lumbar stabilization exercise with the breathing retraining exercise and the group who only performed the lumbar stabilization exercise according to the characteristics of the subjects. Two-way repeated ANOVA was used to determine the changes in the measured variables during the pre-test (before experiment), mid-test (after 3 weeks), and post-test (after 6 weeks) periods of both groups. In the individual effects test, if there was an interaction between groups and times, a one-way repeated analysis of variance was performed for statistical processing. The significance level $\alpha$ was set to 0.05 .

\section{Results}

A total of 30 subjects participated in this study. The general characteristics of the subjects were 8 males and 7 females in the experimental group, and 8 males and 7 females in the control group. The average age was $64.80 \pm 8.78$ years in the experimental group and $68.80 \pm 12.25$ years in the control group. The average age was $64.80 \pm 8.78$ years in the experimental group and $68.80 \pm 12.25$ years in the control group. The average height and weight, and body mass index were $163.80 \pm 9.48 \mathrm{~cm}, 61.73 \pm 8.89 \mathrm{~kg}, 22.80 \pm 3.16 \mathrm{~kg} / \mathrm{m}^{2}$ in the experimental group and $162.60 \pm 8.65 \mathrm{~cm}, 58.47 \pm 9.38 \mathrm{~kg}$, $22.10 \pm 2.30 \mathrm{~kg} / \mathrm{m}^{2}$ in the control group. The onset duration was $13.33 \pm 3.15$ months in the experimental group and $12.80 \pm 2.81$ months in the control group. There were no significant differences between the groups according to the homogeneity and normality test $(p>0.05)$ (Table 2$)$.

In comparing the quality of life of each group, there was no statistically significant difference in the main effect test between the 2 groups $(p>0.05)$. There was no statistically significant difference in the interaction between the group and the experimental period ( $p>0.05$ ). However, there was a significant difference in the main effect test in the test after 6 weeks according to the experimental period $(p<0.05)$ (Table 3).

\section{Discussion}

In this study, lumbar stabilization exercises and breathing retraining exercises using a pressure biofeedback device

Table 2. General characteristics of the subjects

$(\mathrm{N}=30)$

\begin{tabular}{lccr}
\hline \multicolumn{1}{c}{ Characteristics } & EG group $(\mathrm{n}=15)$ & CG group $(\mathrm{n}=15)$ & $\mathrm{t}(p)$ \\
\hline Sex (male/female) & $8 / 7$ & $8 / 7$ & $<0.001(1.000)$ \\
Affected side (right/left) & $6 / 9$ & $6 / 9$ & $<0.001(1.000)$ \\
Age $(\mathrm{y})$ & $64.80(8.78)$ & $68.80(12.25)$ & $-1.027(0.313)$ \\
Height $(\mathrm{cm})$ & $163.80(9.48)$ & $162.60(8.65)$ & $0.434(0.668)$ \\
Weight $(\mathrm{kg})$ & $61.73(8.89)$ & $58.47(9.38)$ & $0.979(0.336)$ \\
BMI $\left(\mathrm{kg} / \mathrm{m}^{2}\right)$ & $22.80(3.16)$ & $22.10(2.30)$ & $0.645(0.524)$ \\
Onset duration (mo) & $13.33(3.15)$ & $12.80(2.81)$ & $0.489(0.629)$ \\
\hline
\end{tabular}

Values are presented as number only or mean (SD).

BMI: body mass index, EG: experimental group, CG: control group.

${ }^{*} p<0.05$.

Table 3. A comparison of SS-QOL intervention period on each group

\begin{tabular}{lcccccc}
\hline & Pre-test & 3 weeks & 6 weeks & \multicolumn{2}{c}{$F(p)$} & \\
\cline { 5 - 7 } & & & & Period & Group & Group period \\
\hline EG $(\mathrm{n}=15)$ & $150.73(16.61)$ & $144.47(27.31)$ & $132.33(16.72)$ & $21.950(<0.001)$ & $0.926(0.344)$ & $0.667(0.506)$ \\
CG $(\mathrm{n}=15)$ & $159.47(16.34)$ & $144.13(28.48)$ & $141.53(13.74)$ & & & \\
\hline
\end{tabular}

Values are presented as mean (SD).

SS-QOL: stroke-specific quality of life, EG: experimental group, CG: control group. 
were performed in individuals with stroke. Therefore, a pressure biofeedback device was used to investigate how quality of life was affected by the addition of breathing retraining exercises. As a result of the study, the respiration retraining exercise using the pressure biofeedback device for stroke survivors showed a significant difference compared to the group who performed only the lumbar stabilization exercise. It is believed that breathing retraining exercise using a pressure biofeedback device has a positive effect on improving patients' symptoms. According to previous research, as a method to improve trunk muscle strength, it was more effective to strengthen the trunk muscles by directly stimulating the trunk with bridge exercises and the performing the 4-legged posture than applying load onto the distal segment [18]. This researcher believes that the intervention method was correct, and it can be seen as the result of strengthening the deep muscles by strengthening the trunk muscle strength. In addition, to strengthen the body control ability, the interaction between the body and other body segments for dynamic stability is an important purpose [19] and it is related to body stability, which is consistent with previous studies [20]. Therefore, it is thought that a more positive effect can be achieved if the respiratory retraining exercise intervention using a pressure biofeedback device is used in parallel with lumbar stabilization exercises rather than just performing general lumbar stabilization exercises.

SS-QOL reflects the characteristics of stroke survivors and is a quality of life assessment tool suitable for our culture and social environment [21]. In addition, as for the factors that affect life satisfaction or quality of life in stroke survivors, it has been reported in several studies that the performance ability of daily living activities and the tendency to fall into depression are the main factors [22]. According to a previous study, it was reported that impaired physical function and daily life activity performance of stroke survivors also had an affect on depression and negatively affected rehabilitation [23]. On the other hand, it was reported that group activities in these daily life performance abilities formed an interaction between patients with stroke, reducing depression and improving quality of life [24]. After performing trunk stabilization training for these persons with stroke 5 times a week for 6 weeks, the quality of life was evaluated and was significantly improved. It is thought that this had a positive effect on improving the quality of life by having an influence on the formation of interactions of the patients due to the bridge exercise, the lifting of the head on the stable support surface, and the lifting of the upper body.
In conclusion, the quality of life improved on average in both the experimental group and the control group after intervention in this study, but there was no significant difference. However, there were significant differences in both groups during the experiment. This difference is thought to have occurred because the duration and method of intervention were different.

As a limitation of this study, the control variables other than the patient's treatment time were not considered, and the number of subjects was not large, so it is considered that there is a limit to generalizing the results using the minimum number of people. The experimental period was also composed of a short period of 6 weeks, therefore long-term effects were not investigated.

Therefore, it is necessary to analyze a variety of subjects as a sample, and it is thought that it will be of great help in proving the effect if further investigations include a longer exercise period or investigations on the effect on depression are made.

\section{Conflict of Interest}

The authors declared no potential conflicts of interest with respect to the research, authorship, and/or publication of this article.

\section{References}

1. Roh SG, Kim JH. Acute cerebrovascular accident in Korea. J Korea Converg Soc 2012;3:23-8.

2. Trombly CA, Radomski MV, Trexel C, Burnet-Smith SE. Occupational therapy and achievement of self-identified goals by adults with acquired brain injury: phase II. Am J Occup Ther 2002;56:489-98.

3. Mun BM, Lee YS, Lee BH. The relationship between the patient's health beliefs and the implementation of functional movement rehabilitation and ability to perform ADL in stroke patients. J Korea Acad Ind Soc 2012;13:3057-64.

4. Canning CG, Ada L, Adams R, O'Dwyer NJ. Loss of strength contributes more to physical disability after stroke than loss of dexterity. Clin Rehabil 2004;18:300-8.

5. Faria-Fortini I, Michaelsen SM, Cassiano JG, Teixeira-Salmela LF. Upper extremity function in stroke subjects: relationships between the international classification of functioning, disability, and health domains. J Hand Ther 2011;24:257-64; quiz 265.

6. Robinson CA, Shumway-Cook A, Matsuda PN, Ciol MA. Understanding physical factors associated with participation in community ambulation following stroke. Disabil Rehabil 2011; 33:1033-42.

7. Park JB, An SH. The effects of exercise on lumvar stabilization and a complex exercise in muscle, pains and index of disabilities 
in activities of chronic low back pain. Korean J Sports Sci 2017; 26:1019-31.

8. Dj M, editor Instability and stabilization Theory and treatment. 2nd Seminar Workbook; 1999.

9. Barr KP, Griggs M, Cadby T. Lumbar stabilization: core concepts and current literature, Part 1. Am J Phys Med Rehabil 2005; 84:473-80.

10. Behm DG, Drinkwater EJ, Willardson JM, Cowley PM. The use of instability to train the core musculature. Appl Physiol Nutr Metab 2010;35:91-108.

11. Lee GC, Kim CH, Sin EM, Choi SH, Jang C. The effect of lumbar stabilization exercise using pressure biofeedback on academy teacher with low back pain. J Korean Soc Sports Phys Ther 2010; 6:49-57.

12. Jull G, Richardson C, Toppenberg R, Comerford M, Bui B. Towards a measurement of active muscle control for lumbar stabilisation. Aust J Physiother 1993;39:187-93.

13. Mills JD, Taunton JE, Mills WA. The effect of a 10-week training regimen on lumbo-pelvic stability and athletic performance in female athletes: a randomized-controlled trial. Phys Ther Sport 2005;6:60-6.

14. Andersson GB. Epidemiologic aspects on low-back pain in industry. Spine (Phila Pa 1976) 1981;6:53-60.

15. Kim HS, Kim YS. A study on the quality of life, self-efficacy and family support of stroke patients in Oriental medicine hospitals. J Korean Soc Health Educ Promot 2003;20:111-30.

16. Chang JS, Lee JH. Comparison of cervical flexor muscles thickness during cranial-cervical flexor exercise according to pressure levels and eye directions in healthy subjects. J Korean Phys Ther 2015;27:50-4.

17. Williams LS, Weinberger M, Harris LE, Clark DO, Biller J. Development of a stroke-specific quality of life scale. Stroke 1999;30:1362-9.

18. Oh G, Lee H. The effects of the task-oriented trunk training on muscle strength and muscle activity of trunk, balance and gait in stroke patients. J Korean Soc Integr Med 2020;8:203-17.

19. Edwards S, Charlton PD. Splinting and the use of orthoses in the management of patients with neurological disorders. In: Edwards S, editor. Neurological physiotherapy: a problem-solving approach. 2nd ed. Edinburgh, New York (NY): Churchill Livingstone; 2002. p. 219-53.

20. Cabanas-Valdés R, Cuchi GU, Bagur-Calafat C. Trunk training exercises approaches for improving trunk performance and functional sitting balance in patients with stroke: a systematic review. NeuroRehabilitation 2013;33:575-92.

21. Hobart JC, Williams LS, Moran K, Thompson AJ. Quality of life measurement after stroke: uses and abuses of the SF-36. Stroke 2002;33:1348-56.

22. King RB. Quality of life after stroke. Stroke 1996;27:1467-72.

23. Hackett ML, Yapa C, Parag V, Anderson CS. Frequency of depression after stroke: a systematic review of observational studies. Stroke 2005;36:1330-40.

24. Baum EE, Jarjoura D, Polen AE, Faur D, Rutecki G. Effectiveness of a group exercise program in a long-term care facility: a randomized pilot trial. J Am Med Dir Assoc 2003;4:7480 . 